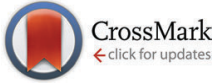

Cite this: J. Mater. Chem. C, 2016 4, 1829

Received 6th January 2016 Accepted 27th January 2016

DOI: $10.1039 / c 6 t c 00069$

www.rsc.org/MaterialsC

\section{Thermal stability and electrical conductivity of carbon-enriched silicon oxycarbide}

\begin{abstract}
Kathy Lu,* Donald Erb and Mengying Liu
Silicon oxycarbide (SiOC) is an interesting polymer-derived system that can be tailored to embody many different properties such as lightweight, electrochemical activity, and high temperature stability. One intriguing property that has not been fully explored is the electrical conductivity for the carbon-rich SiOC compositions. In this study, a carbon-rich SiOC system is created based on the crosslinking and pyrolysis of polyhydromethylsiloxane (PHMS) and divinylbenzene (DVB) mixed precursors. The carbonrich nature can effectively delay $\mathrm{SiOC}$ phase separation and crystallization into $\mathrm{SiO}_{2}$ and $\mathrm{SiC}$ during pyrolysis. In an oxidizing air atmosphere, the SiOC materials are stable up to $1000{ }^{\circ} \mathrm{C}$ with $<0.5$ wt\% weight loss. Before the onset of electrical conductivity drop at $\sim 400{ }^{\circ} \mathrm{C}$, the material has electrical conductivity as high as $4.28 \mathrm{~S} \mathrm{~cm}^{-1}$. In an inert argon atmosphere, the conductivity is as high as $4.64 \mathrm{~S} \mathrm{~cm}^{-1}$. This new semi-conducting behavior with high thermal stability presents promising application potential for high temperature MEMS devices, protective coatings, and bulk semi-conducting components that must endure high temperature conditions.
\end{abstract}

\section{Introduction}

Silicon oxycarbide (SiOC) is an interesting system where novel properties can be created because the compositions and structures of the final materials can be designed from the molecular level based on polymer precursor compositions as well as crosslinking and pyrolysis conditions. ${ }^{1,2}$ In the $\mathrm{SiOC}$ structure, $\mathrm{SiO}_{x} \mathrm{C}_{4-x}$ units are believed to form a fractal network, in which oxygen and some of the carbon atoms are bonded randomly to silicon in a threedimensional covalent structure, forming $\mathrm{SiO}_{4}, \mathrm{CSiO}_{3}, \mathrm{C}_{2} \mathrm{SiO}_{2}$, $\mathrm{C}_{3} \mathrm{SiO}$, and $\mathrm{C}_{4} \mathrm{Si}^{3}{ }^{3}$ It is generally assumed that carbon and oxygen cannot bond to each other. Depending on the pyrolysis temperature, the system can be described as a nanocomposite formed by a silicon oxycarbide $\left(\operatorname{SiC}_{x} \mathrm{O}_{y}\right)$ matrix in which free, turbostratic carbon is dispersed, and $\mathrm{SiO}_{2}$ or $\mathrm{SiO}_{2}$ plus $\mathrm{SiC}$ nanoclusters may be present. ${ }^{4-7}$ SiOC glasses studied so far usually contain excess $\mathrm{C}$, and their compositions can be expressed as $\mathrm{SiO}_{2(1-x)} \mathrm{C}_{x}+y \mathrm{C}_{\text {free, }}$, where $x+y$ is the molar ratio of the carbon relative to the silicon content. ${ }^{8}$ Due to the merit of shaping at low temperatures through liquid polymer precursor processes, SiOC can be processed into different bulk shapes and sizes, coatings, or even powders to meet various needs. ${ }^{9}$

SiOC systems have been considered as electrode materials (anode) in Li-ion batteries. ${ }^{10-13}$ However, they have not attracted wide attention as self-standing conducting materials. In general,

Department of Materials Science and Engineering, Virginia Polytechnic Institute and State University, Blacksburg, VA 24061, USA. E-mail: klu@vt.edu;

Fax: +1540 231 8919; Tel: +15402313225 carbon-rich polysiloxanes and other precursor additives enhance the crosslinking ability. However, it is commonly understood that free-carbon leads to lower thermal stability. ${ }^{3,14,15}$ Even though carbon-rich SiOC systems can provide some electrical conductivity, the overall low values $\left(\sim 1 \times 10^{-3} \mathrm{~S} \mathrm{~cm}^{-1}\right)$ have not generated much interest. ${ }^{16}$ Much higher carbon contents are needed if SiOC is to be used as an electrically conductive material. ${ }^{3,17,18}$ As a result of this motivation, fully dense and crack-free SiOC ceramics were prepared by direct photo-crosslinking and pyrolysis of a polysiloxane. The samples showed high content (78-86 mol\%) of segregated "free" carbon. ${ }^{19}$ The dc resistivity of the prepared material at $1100{ }^{\circ} \mathrm{C}$ was $2.86 \mathrm{~S} \mathrm{~m}^{-1}$, whereas the ceramic pyrolyzed at $1400{ }^{\circ} \mathrm{C}$ showed a value of $7.14 \mathrm{~S} \mathrm{~m}^{-1}$. The latter feature was attributed to the presence of a percolating carbon network in the ceramic. To enhance carbon segregation, much higher pyrolysis was also sought. The SiOC ceramics sintered at $1650{ }^{\circ} \mathrm{C}$ exhibited an electrical conductivity of $700 \mathrm{~S} \mathrm{~m}^{-1}$ at room temperature..$^{20}$ However, if high thermal stability is sought, low or zero free-carbon contents are desirable. With the formation of free carbon in SiOC, the SiOC system can be oxidized at high temperatures, compromising its thermal stability and thus its electrical conductivity. ${ }^{21}$ Because of these antagonistic behaviors, there has been almost no interest in examining high carbon content SiOCs for high temperature electrical conductivity purposes.

A surprising finding that has not caused as much attention as it deserves is the high temperature stability of carbon-rich SiOCs created based on polyhydromethylsiloxane (PHMS) and carbon-rich additive divinylbenzene (DVB). Kleebe and Blum reported that the resulting carbon-rich SiOC ceramics are stable 
up to $1000{ }^{\circ} \mathrm{C}$ despite the existence of high amounts of freecarbon. ${ }^{14,22}$ This led us to ponder whether it is possible to obtain a SiOC system possessing high thermal stability and high electrical conductivity simultaneously. The unknown relationships between composition, thermal stability, and electrical conductivity present not only scientific intrigues but also new application potential. ${ }^{23,24}$ The tunable electrical properties together with microfabrication ability and excellent high thermal stability may make the SiOC systems excellent candidates for high temperature sensors, MEMS devices, conductivity coating, and so on.

This research is to explore the ceramization, phase evolution, thermal stability, and electrical conductivity of this family of high carbon-containing SiOCs. Our intent is to understand their composition-microstructure-thermal stability-electrical conductivity relationships. The influence of pyrolysis temperature and carbon content on microstructure, oxidation resistance, and electrical conductivity is systematically studied. It provides the first study and exciting new data on the hindered phase evolution, high thermal stability, and high electrical conductivity of these carbonrich SiOCs.

\section{Experimental section}

In this study, polyhydromethylsiloxane (PHMS, Gelest Inc., Morrisville, PA) was chosen as the precursor, divinylbenzene (DVB, Sigma-Aldrich, St. Louis, MO) was used as the crosslinking agent and carbon content enhancer, and the $2.1-2.4 \%$ platinum-divinyltetramethyldisiloxane complex in xylene ( $\mathrm{Pt}$ catalyst, Gelest Inc., Morrisville, PA) was used as the catalyst. First, DVB was added into PHMS and magnetically stirred at $400 \mathrm{rpm}$ for $30 \mathrm{~min}$ to form a homogeneous mixture. The DVB contents used were $0,20,40,60$, and $80 \mathrm{wt} \%$ relative to the PHMS weight. The mixture before crosslinking was a slightly yellow, transparent liquid containing small bubbles. Next, the diluted Pt catalyst (5 ppm relative to PHMS) was introduced into the mixture. The mixture was then cast in an aluminum mold and placed in a vacuum chamber until 1500 mTorr to remove all the bubbles. The mixture was then put in an oven to degas and cure at $50{ }^{\circ} \mathrm{C}$ for $12 \mathrm{~h}$, at $80{ }^{\circ} \mathrm{C}$ for $10 \mathrm{~h}$, and at $120{ }^{\circ} \mathrm{C}$ for $6 \mathrm{~h}$. When crosslinking PHMS with $0 \mathrm{wt} \% \mathrm{DVB}$, only $2.5 \mathrm{ppm}$ of the above diluted Pt catalyst solution was added in order to slow down the crosslinking (gas generation) and thus avoid defect formation; the $0 \mathrm{wt} \%$ DVB samples were degassed and cured at $50{ }^{\circ} \mathrm{C}$ for $24 \mathrm{~h}$, at $80{ }^{\circ} \mathrm{C}$ for $24 \mathrm{~h}$, and at $120{ }^{\circ} \mathrm{C}$ for $6 \mathrm{~h}$ to obtain crack-free samples. The materials after crosslinking were hard, rubbery, and transparent.
To prepare the samples for pyrolysis, the cured materials were first cut and polished to roughly $10 \mathrm{~mm} \times 10 \mathrm{~mm} \times$ $1.5 \mathrm{~mm}$ size. Next, the samples were placed in a zirconia boat, covered on both sides with graphite mats and put into a tube furnace (1730-12 Horizontal Tube Furnace, CM Furnaces Inc.,

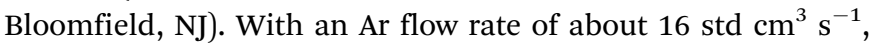
the samples were heated up to $800{ }^{\circ} \mathrm{C}$ with a rate of $1^{\circ} \mathrm{C} \mathrm{min}^{-1}$, held at this temperature for $2 \mathrm{~h}$, and then pyrolyzed up to $1200{ }^{\circ} \mathrm{C}, 1300{ }^{\circ} \mathrm{C}$, or $1400{ }^{\circ} \mathrm{C}$ at a rate of $1{ }^{\circ} \mathrm{C} \mathrm{min}{ }^{-1}$ with $2 \mathrm{~h}$ holding. The shrinkage, ceramic yield, and density of the samples during pyrolysis were tracked. The ceramic yield was obtained based on the ratio of the weight after pyrolysis versus the weight before pyrolysis. The density was obtained by measuring the weight and dimensions of the pyrolyzed samples.

Phase compositions of the pyrolyzed samples were analyzed using an X'Pert PRO diffractometer (PANalytical B.V., EA Almelo, The Netherlands). For the stoichiometry analysis of the SiOC samples, a combustion method was used to analyze the content of carbon. Acid digestion and titration were used to obtain the silicon content. The oxygen content was extracted based on the above results and the total mass of the samples. These experiments were conducted by Galbraith Laboratories, Inc. (Knoxville, TN). The thermal stability of the SiOC samples after pyrolysis was investigated by differential scanning calorimetry (DSC) and thermogravimetric analysis (TGA) using an STA 449C Jupiter ${ }^{\circledR}$ analyzer (NetzschGerätebau $\mathrm{GmbH}$, Selb, Germany) from room temperature to $1000{ }^{\circ} \mathrm{C}$ at a heating rate of $5{ }^{\circ} \mathrm{C} \mathrm{min}{ }^{-1}$ and an air flux of $40 \mathrm{ml}$ $\min ^{-1}$. The electrical conductivity of the samples was measured in both air and Ar environments from room temperature up to $800{ }^{\circ} \mathrm{C}$ in a four-point probe configuration using a potentiostat (VersaSTAT 3, Princeton Applied Research, Oak Ridge, TN). A field emission SEM (LEO 1550, Carl Zeiss MicroImaging, Inc., Thornwood, NY) was used to characterize the microstructures of the pyrolyzed samples.

\section{Results and discussion}

\subsection{Thermophysical properties}

The bulk samples after pyrolysis at different temperatures are black and defect-free. The unpolished surfaces are smooth and light reflecting, and the polished surface is totally black. Table 1 shows the volume shrinkage, ceramic yield, and density values for the samples after pyrolysis.

The 0 wt $\%$ DVB samples pyrolyzed at $1200{ }^{\circ} \mathrm{C}$ have cracks after pyrolysis, so no volume shrinkage values are available for those samples; the volume shrinkage values for all other samples

Table 1 Volume shrinkage, ceramic yield, and density of pyrolyzed SiOC samples

\begin{tabular}{|c|c|c|c|c|c|c|c|c|c|}
\hline $\begin{array}{l}\text { DVB content } \\
(\mathrm{wt} \%)\end{array}$ & \multicolumn{3}{|c|}{ Volumetric shrinkage (\%) } & \multicolumn{3}{|c|}{ Ceramic yield (\%) } & \multicolumn{3}{|c|}{ Density $\left(\mathrm{g} \mathrm{cm}^{-3}\right)$} \\
\hline 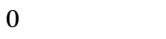 & N/A & & & $88.26 \pm 2.13$ & $91.83 \pm 1.60$ & $86.19 \pm 5.08$ & N/A & $1.54 \pm$ & \\
\hline 40 & $49.75 \pm 2.10$ & $49.14 \pm 2.64$ & $47.20 \pm 2.65$ & $85.91 \pm 0.85$ & $86.68 \pm 0.46$ & $86.38 \pm 0.50$ & $1.52 \pm 0.44$ & $1.68 \pm 0.02$ & $1.76 \pm 0.11$ \\
\hline 60 & $51.80 \pm 2.15$ & $50.58 \pm 0.09$ & $50.46 \pm 1.70$ & $83.36 \pm 0.11$ & $83.47 \pm 0.14$ & $83.11 \pm 0.37$ & $1.86 \pm 0.14$ & $1.71 \pm 0.00$ & $1.82 \pm 0.12$ \\
\hline 80 & $52.04 \pm 4.46$ & $50.90 \pm 1.79$ & $53.19 \pm 1.23$ & $79.65 \pm 0.63$ & $79.55 \pm 0.10$ & $79.36 \pm 0.49$ & $1.76 \pm 0.27$ & $1.67 \pm 0.10$ & $1.94 \pm 0.36$ \\
\hline
\end{tabular}


are in the range of $38-53 \%$. At the same pyrolysis temperature, as the DVB content increases, the volume shrinkage also increases. The overall volume shrinkage increases from $\sim 39$ vol\% to $\sim 52$ vol\% when the DBV content increases from $0 \mathrm{wt} \%$ to $80 \mathrm{wt} \%$. However, some of the volume shrinkage values at different DVB contents overlap when the standard deviation is considered. Thus, only the general trend is valid. For the same DVB content, the volume shrinkage shows no general trend with an increase in pyrolysis temperature from $1200{ }^{\circ} \mathrm{C}$ to $1400{ }^{\circ} \mathrm{C}$. In general, these results mean fairly large volume shrinkage for the SiOC system. Surprisingly, intact and defect-free bulk samples are still obtained except for the $0 \mathrm{wt} \%$ DVB samples pyrolyzed at $1200{ }^{\circ} \mathrm{C}$.

The ceramic yield values for all the samples range from 79 to $91 \%$. At the same pyrolysis temperature, an increase in the DVB content results in a decrease in the ceramic yield. This is understandable in light of the carbon-enhancing effect from DBV. It is reported that different groups on the crosslinked polymer have different effects on the ceramic yield. ${ }^{3}$ When adding more DVB into the sample, the phenyl groups lead to more volatile species and pyrolyze into more free carbon when pyrolyzed at high temperatures. More carbon formation in general leads to a lower ceramic yield. The ceramic yield trend is also consistent with the volume shrinkage and the bulk density (an increase in volumetric shrinkage and bulk density with the increase in DVB content). For the same DVB content, the ceramic yield shows no general trend (and thus similar values) as the pyrolysis temperature increases. This means that after the SiOC formation at $1200{ }^{\circ} \mathrm{C}$ and higher temperatures, the overall SiOC system remains stable in a wide temperature range (up to at least $1400{ }^{\circ} \mathrm{C}$ ) in an inert $\mathrm{Ar}$ atmosphere. The only potential changes are phase separation as discussed in Fig. 1.

The densities for all the SiOC samples are in the range of 1.5-1.95 $\mathrm{g} \mathrm{cm}^{-3}$. At the same pyrolysis temperature, higher DVB content generally leads to higher bulk density. Even though this trend is consistent with the volumetric shrinkage, it is still a bit surprising since higher carbon content in SiOC in general should lead to lower density. The decreasing ceramic yield seems to indicate that there is indeed more carbon loss for higher DVB content samples and may diminish the possible effect of the DVB content. However, the impact is not significant enough to affect the resulting densities. To understand this result more clearly, quantification of the SiOC compositions is detailed next, showing that both SiOC and carbon, and even $\mathrm{SiO}_{2}$, have influence on the density. With the increase in pyrolysis temperature, there is no clear density change. This is consistent with the volumetric shrinkage and density changes as well as the understanding that volatile species loss during $1200-1400{ }^{\circ} \mathrm{C}$ pyrolysis is negligible.

Summarizing the results in Table 1 , it can be stated that the volumetric shrinkage increases with the DVB (and thus carbon) content; the ceramic yield decreases with the DVB (and thus carbon) content; however, the bulk density also generally increases with the DVB (and thus carbon) content. The shrinkage, ceramic yield, and density of the resulting SiOC samples remain relatively stable and experience little change in the wide temperature range of $1200-1400{ }^{\circ} \mathrm{C}$. Even though it is generally accepted that higher
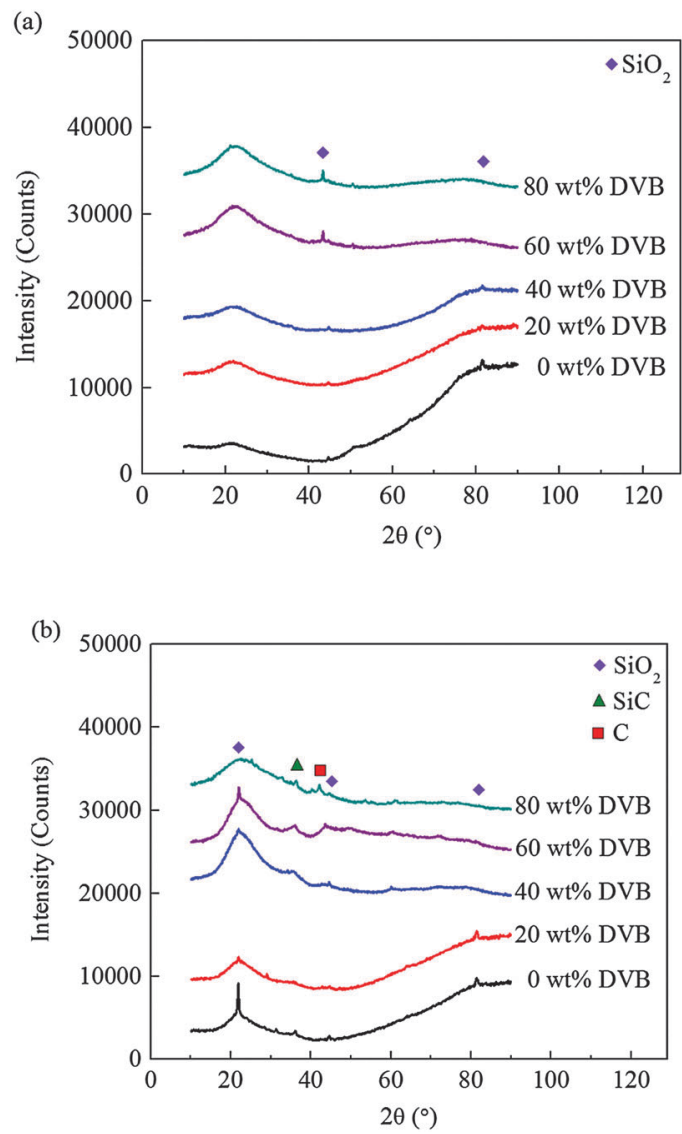

Fig. 1 XRD patterns of SiOCs for different DBV contents at (a) $1200^{\circ} \mathrm{C}$ and (b) $1400{ }^{\circ} \mathrm{C}$ pyrolysis temperatures.

pyrolysis temperature and more carbon-containing precursors (in this study DVB) should lead to larger shrinkage and lower ceramic yield, the current work shows that the carbon loss is significantly hindered. This family of SiOC materials demonstrates the unique ability of restricting carbon loss at high pyrolysis temperatures.

For the SiOC samples pyrolyzed at $1200{ }^{\circ} \mathrm{C}$ and $1400{ }^{\circ} \mathrm{C}$, the compositions are shown in Table 2 with varying DVB contents. At both $1200{ }^{\circ} \mathrm{C}$ and $1400{ }^{\circ} \mathrm{C}$ temperatures, the carbon content increases with the increase in DVB content. At $1200{ }^{\circ} \mathrm{C}$, the carbon content increases from $10.69 \mathrm{wt} \%$ to $28.54 \mathrm{wt} \%$ with $0 \mathrm{wt} \%$ DVB to $80 \mathrm{wt} \%$ DVB addition. At $1400{ }^{\circ} \mathrm{C}$, the carbon content increases from $3.98 \mathrm{wt} \%$ to $21.98 \mathrm{wt} \%$ with $0 \mathrm{wt} \% \mathrm{DVB}$ to $80 \mathrm{wt} \%$ DVB addition. This is expected because DVB is a carbon-content enhancer. Not surprisingly, higher pyrolysis temperature also leads to less carbon as carbon-containing volatile species are more likely to escape at higher temperatures. However, it is surprising to find that the oxygen contents are high and decrease only slightly (at $1200{ }^{\circ} \mathrm{C}$ ) or remain consistent (at $1400{ }^{\circ} \mathrm{C}$ ) with the increase in DVB content. Higher pyrolysis temperature leads to higher oxygen content. At $1200{ }^{\circ} \mathrm{C}$, the oxygen content is $45.5 \mathrm{wt} \%$ to $34.1 \mathrm{wt} \%$ with $0 \mathrm{wt} \% \mathrm{DVB}$ to $80 \mathrm{wt} \%$ DVB addition. At $1400{ }^{\circ} \mathrm{C}$, the oxygen content is $51.4 \mathrm{wt} \%$ to $42.7 \mathrm{wt} \%$ with 0 wt $\%$ DVB to $80 \mathrm{wt} \%$ DVB addition. On a molar basis, the SiOC compositions can be expressed as $\mathrm{SiO}_{2(1-x)} \mathrm{C}_{x}+y \mathrm{C}_{\text {free }}$, where $x+y$ is the molar ratio of the carbon relative to the silicon 
Table 2 SiOC compositions at $1200^{\circ} \mathrm{C}$ and $1400{ }^{\circ} \mathrm{C}$ pyrolysis temperatures

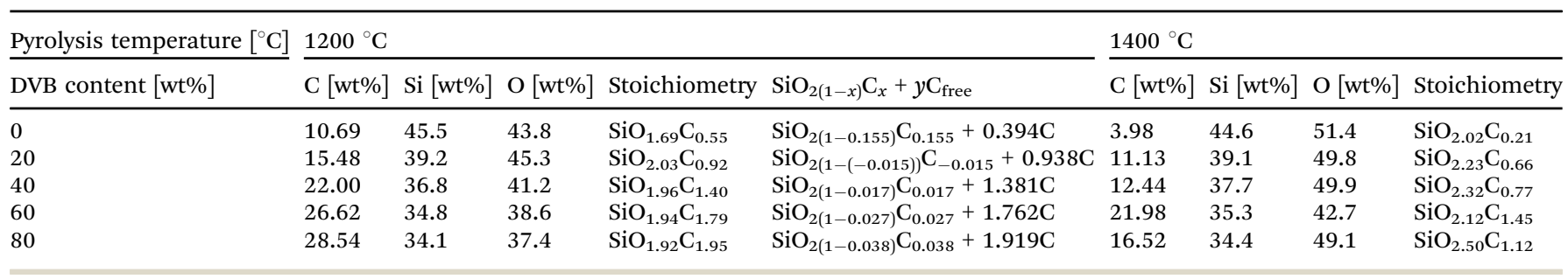

content, under the assumption that there is no further phase separation into $\mathrm{SiO}_{2}$ or SiC. Based on Fig. 1(a), there is little $\mathrm{SiO}_{2}$ present in any of the samples at $1200{ }^{\circ} \mathrm{C}$; thus, their compositions can be expressed with the above formula, as shown in Table 2 . With $0 \mathrm{wt} \% \mathrm{DVB}$, the SiOC is slightly carbon rich. With the increase in DVB content, carbon becomes more excessive. At $80 \mathrm{wt} \%$ DVB, the excessive carbon is $1.92: 1$ compared to SiOC on a molar basis. At $1400{ }^{\circ} \mathrm{C}$ pyrolysis temperature, a much higher amount of $\mathrm{SiO}_{2}$ is formed as shown in Fig. 1(b). Thus, the overall composition cannot be expressed as $\mathrm{SiO}_{2(1-x)} \mathrm{C}_{x}+y \mathrm{C}_{\text {free }}$ even though the carbon-rich nature remains the same. With the increase in DVB content from $0 \mathrm{wt} \%$ to $80 \mathrm{wt} \%$, the carbon content keeps increasing. The corresponding high oxygen content also means that a significant amount of $\mathrm{SiO}_{4}, \mathrm{SiO}_{3} \mathrm{C}$, and $\mathrm{SiO}_{2} \mathrm{C}_{2}$ may exist.

In Table 2, it should be pointed out that the carbon content result for the $60 \mathrm{wt} \% \mathrm{DVB}$ sample under $1400{ }^{\circ} \mathrm{C}$ conditions is not ideally consistent with the other samples at the same temperature. We have re-tested the $\mathrm{C}$ content three times (five samples). It cannot be excluded that this sample might have some peculiarity but the general trend should still be valid.

Fig. 1 shows the SiOC phase evolution from $1200{ }^{\circ} \mathrm{C}$ to $1400{ }^{\circ} \mathrm{C}$ pyrolysis temperature for the five levels of DVB contents studied. At $1200{ }^{\circ} \mathrm{C}$ (Fig. 1(a)), for $0 \mathrm{wt} \%, 20 \mathrm{wt} \%$, and $40 \mathrm{wt} \%$ DVB samples, two minor peaks are observed at $44.5^{\circ}$ and $81.4^{\circ}$. They are identified as the diffraction peaks of orthorhombic $\mathrm{SiO}_{2}$. The halo at $22^{\circ}$ is attributed to amorphous $\mathrm{SiO}_{2}$. From the XRD patterns, it can be stated that the samples are largely amorphous. With the increase in DVB content to $60 \mathrm{wt} \%$ and $80 \mathrm{wt} \%$, the diffraction peak at $81.4^{\circ}$ disappears. The halo at $22^{\circ}$ increases. Only one peak at $44.5^{\circ}$ is detected, which can still be attributed to the orthorhombic $\mathrm{SiO}_{2}$ phase. This means that higher DVB (and thus more carbon) content hinders the crystallization of $\mathrm{SiO}_{2}$. As a result, the $22^{\circ}$ halo increases, which is an indication of the dominance of amorphous $\mathrm{SiO}_{2}$.

When the pyrolysis temperature increases to $1300{ }^{\circ} \mathrm{C}$ (the XRD pattern plots are eliminated for brevity), the diffraction patterns show no significant changes compared to those at $1200{ }^{\circ} \mathrm{C}$ (Fig. 1(a)). The phase transformation trend remains the same with the change in DVB content. This means that the SiOC structures remain unchanged and the SiOC systems continue to resist $\mathrm{SiO}_{2}$ phase separation. At $1400{ }^{\circ} \mathrm{C}$ pyrolysis temperature (Fig. 1(b)), the increase in DVB content and thus the higher free carbon content continue to hinder $\mathrm{SiO}_{2}$ crystallization based on the $22^{\circ}$ diffraction peak. In comparison, the $\mathrm{SiC}$ and $\mathrm{C}$ phases start to appear. Overall, the weak diffraction peaks indicate that the SiOC materials are dominated by the amorphous SiOC matrix.
Throughout the pyrolysis temperature range of $1200-1400{ }^{\circ} \mathrm{C}$, a surprising finding is the lack of the SiC phase at all the DVB levels. As known, the onset of crystallization for $\beta$-SiC in SiOC is dependent on the amount of carbon. For the SiOCs with lower $\mathrm{C}$ content, $\sim 5 \mathrm{wt} \%$ of $\beta$-SiC crystalline phase can be detected at $1200{ }^{\circ} \mathrm{C}$, whereas for the carbon-rich SiOC the pyrolysis temperature must be increased up to $1400{ }^{\circ} \mathrm{C}$ to promote crystallization. ${ }^{8}$ In this studied system, no $\mathrm{SiC}$ is detected even at $1400{ }^{\circ} \mathrm{C}$ and the $\mathrm{SiO}_{2}$ diffraction peaks become strong only at $1400{ }^{\circ} \mathrm{C}$. This again agrees with our earlier observation of carbon hindering SiOC phase separation and crystallization. ${ }^{25}$ With the homogeneous mixing of polymer precursors PHMS and DVB, this delayed $\mathrm{SiO}_{2}$ crystallization seems to be especially obvious. With the higher carbon content in this study, SiC crystallization can be delayed beyond $1400{ }^{\circ} \mathrm{C}$.

Overall, the phase changes for the studied SiOC systems are very sluggish compared to other SiOC systems. The lack of diffraction peaks indicates hindered transformation of the SiOC matrix to $\mathrm{SiO}_{2}$ and $\mathrm{SiC}$ materials. The overall SiOC material behaviors remain to be determined by the SiOC phase stoichiometry and excessive carbon. The reason can be attributed to the diffusion hindrance from the free carbon for $\mathrm{Si}$ and thus $\mathrm{SiO}_{2}$ and $\mathrm{SiC}$ formation. Our conjecture is that the free carbon phase and the fractal SiOC phase form an intertwining structure, which can effectively suppress the Si diffusion as well as carbon loss. This interlocking structure demonstrates relatively stable shrinkage, ceramic yield, and bulk density in the wide temperature range of $1200-1400{ }^{\circ} \mathrm{C}$. It also results in only a limited amount of $\mathrm{SiO}_{2}$ formation and delayed SiC formation.

As the support for the above conjecture, the SEM images for the $0 \mathrm{wt} \%$ and $80 \mathrm{wt} \%$ DVB samples after $1400{ }^{\circ} \mathrm{C}$ pyrolysis are shown in Fig. 2. Except for some polishing defects, the overall microstructure is featureless. This observation supports the amorphous nature of the SiOCs. Even though some $\mathrm{SiO}_{2}$ crystallization is observed in Fig. 1, the SEM images do not show such phase, probably because of the SEM resolution limit.

\subsection{Thermal stability}

SiOC is known for its thermal stability in inert atmospheres up to $1300{ }^{\circ} \mathrm{C}$. In this study, the major focus on the thermal stability is for the air atmosphere, which is oxidative. Based on the SiOC compositions (free carbon, $\mathrm{SiOC}$, and possibly $\mathrm{SiO}_{2}$ ), there are two sources of instability for SiOC matrices, free turbostratic carbon and SiOC units. In the first case, tiny graphene layers with edge carbon atoms can be oxidized; the radical species on the surface of free carbon can also be oxidized. This could lead to weight loss on 

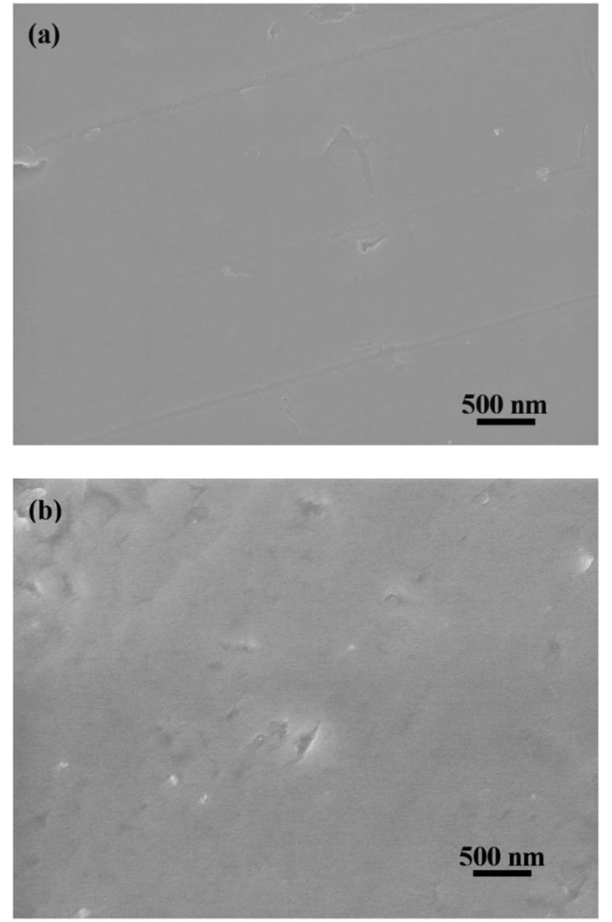

Fig. 2 Featureless microstructures for SiOC samples with (a) $0 \mathrm{wt} \%$ and (b) 80 wt\% DVB after $1400{ }^{\circ} \mathrm{C}$ pyrolysis.

the TGA curves and heat generation on the DSC curves. In the second case, the SiOC units can be oxidized to $\mathrm{SiO}_{2}$ through the transformation of the more oxidation-prone $\mathrm{SiC}_{4}, \mathrm{SiOC}_{3}$, and $\mathrm{SiC}_{2} \mathrm{O}_{2}$ species into $\mathrm{SiO}_{4}$ and $\mathrm{SiO}_{3} \mathrm{C}$ species. Theoretically, the two processes should occur in different temperature ranges because carbon oxidation is relatively easy compared to SiOC oxidation. For the former, the specific oxidation mechanism is the combustion of the free carbon phase:

$$
\mathrm{C}_{\text {free }}+\mathrm{O}_{2} \rightarrow \mathrm{CO}_{x}
$$

For the latter, it can be represented $\mathrm{as}^{26,27}$

$$
\mathrm{SiOC}+\mathrm{O}_{2} \rightarrow \mathrm{SiO}_{2}+\mathrm{CO}_{x}
$$

However, the above simplified assumptions assume that the free carbon and SiOC fractals respond to temperature increase independently. When the carbon and SiOC fractals interlock each other, the independent oxidation processes can be starved off and the effect of the composition of the SiOC system on the oxidation susceptibility needs to be re-examined.

As shown in Fig. 3, the TGA oxidation studies reveal that even at the high carbon content with $80 \%$ DVB addition, the samples are significantly resistant to oxidation in air up to $1000{ }^{\circ} \mathrm{C}$ for the samples pyrolyzed at different temperatures. The maximum weight gain is $<0.5 \mathrm{wt} \%$. These weight loss results are much lower than the $2.5 \mathrm{wt} \%$ weight loss results from the earlier report of Blum et al. ${ }^{14}$ This proves that even for the same SiOC precursor compositions, crosslinking and pyrolysis processes can be fine-tuned to obtain highly stable high carbon content SiOCs. The high miscibility of the polymer precursors and

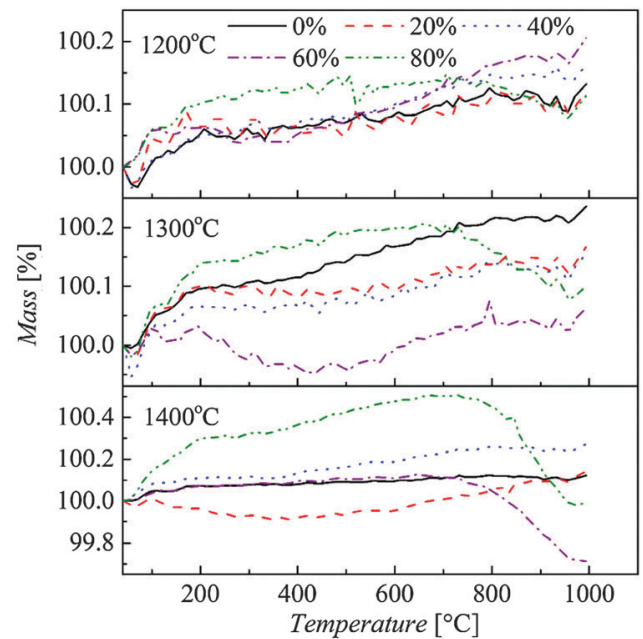

Fig. 3 TGA weight change curves for the SiOCs with different DVB contents and at different pyrolysis temperatures.

the absence of phase separation during crosslinking/pyrolysis enable the excessive turbostratic carbon to be well interspersed in SiOC fractals after high temperature pyrolysis.

On the other hand, the oxidative thermal degradation for the studied SiOC materials has a weak, yet observable correlation with the pyrolysis temperature. ${ }^{28}$ Lower pyrolysis temperatures lead to lower weight changes, at less than $0.2 \mathrm{wt} \%$ at $1200{ }^{\circ} \mathrm{C}$ and $1300{ }^{\circ} \mathrm{C}$ pyrolysis temperatures; at $1400{ }^{\circ} \mathrm{C}$, the weight loss is up to $0.5 \mathrm{wt} \%$. This means that higher pyrolysis temperature leads to less stable SiOC microstructures because of phase separation and thus more oxidation. From $0 \mathrm{wt} \% \mathrm{DVB}$ to $60 \mathrm{wt} \% \mathrm{DVB}$, there is no distinct trend for the weight changes for the $1200{ }^{\circ} \mathrm{C}$ and $1300{ }^{\circ} \mathrm{C}$ pyrolysis temperatures. At $1400{ }^{\circ} \mathrm{C}$ pyrolysis temperature, the $60 \mathrm{wt} \%$ and $80 \mathrm{wt} \%$ DVB samples start to show weight loss at $\sim 780{ }^{\circ} \mathrm{C}$. However, one surprising observation is that the TGA curves mostly show weight gains for different DVB contents and at different pyrolysis temperatures, starting at $200{ }^{\circ} \mathrm{C}$. If carbon oxidation and SiOC oxidation occur in two different temperature ranges (taking $800{ }^{\circ} \mathrm{C}$ as the dividing point; ${ }^{26,27}$ lower than that it is carbon oxidation and higher than that it is SiOC oxidation), then there should be a weight loss peak at low temperatures and then a weight gain peak at high temperatures. However, in this study, a persistent weight gain is observed. The consistent trend of weight gain instead of weight loss might indicate that SiOC oxidation is more dominant except for the $60 \mathrm{wt} \%$ and $80 \mathrm{wt} \%$ DVB samples after $1400{ }^{\circ} \mathrm{C}$ pyrolysis.

To fully understand the high thermal stability of this family of SiOCs, the heat changes through the DSC testing can be used to differentiate the carbon and SiOC oxidation processes. Free carbon should produce exothermic peaks and SiOC oxidation should produce endothermic peaks. However, as shown in Fig. 4, only a broad exothermic peak is observed for the samples at different DVB contents and pyrolysis temperatures. This is believed to result from the oxidation of the dangling bonds on the free carbon and SiOC fractals starting at $\sim 200{ }^{\circ} \mathrm{C}$. When the TGA and DSC curves are considered jointly, we believe that the oxidation of free carbon and SiOC fractals occurs simultaneously; 


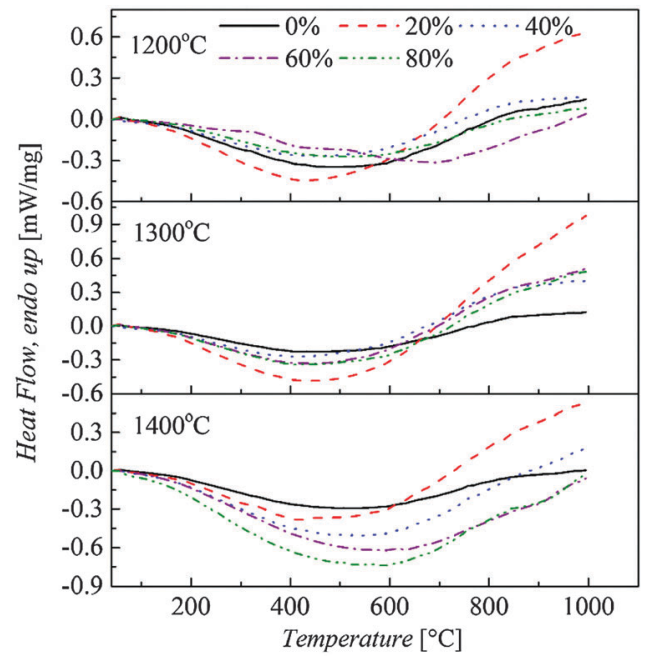

Fig. 4 DSC curves for the SiOCs with different DVB contents and at different pyrolysis temperatures.

the weight shows net gains even though the specific amount is almost negligible while heat generation is detected. With the increase in oxidation temperature, up to around $700-800{ }^{\circ} \mathrm{C}$, the DSC curves continue to show heat generation with consistent minor weight gains based on the TGA curves, consistent with simultaneous oxidation of free carbon and SiOC, at an extremely slow, negligible pace as shown by the very small up-tilting of the TGA weight gain curves. The conjecture is that $\mathrm{SiC}_{4}, \mathrm{SiC}_{3} \mathrm{O}$, and $\mathrm{SiC}_{2} \mathrm{O}_{2}$ structural units disappear as a result of oxidation. At the same time, $\mathrm{SiCO}_{3}$ and $\mathrm{SiO}_{4}$ units increase with oxidation. However, up to now, there has been no suitable technique to illustrate the details of the SiOC evolution process unambiguously.

As stated, the most sensitive issues for SiOC stability degradation are the oxidation of free carbon and the oxidative breakdown of the SiOC structure. For our studied systems, desirably such processes can be suppressed by creating an interlocking structure of free carbon and SiOC fractals. Even under oxidizing conditions up to $1000{ }^{\circ} \mathrm{C}$, the weight loss is $<0.5 \mathrm{wt} \%$ for all the samples. We believe that the interlocking of the free carbon and SiOC clusters is the striking advantage of this SiOC system. Along this line, another surprising finding is the lower thermal stability of the SiOC samples pyrolyzed at higher temperatures (such as $1400{ }^{\circ} \mathrm{C}$ ). The explanation is that higher pyrolysis temperatures lead to more extensive phase separation and less interlocking structures for the free carbon and SiOC. For the studied high carbon content system (60 wt\% and $80 \mathrm{wt} \%$ DVB), high pyrolysis temperatures lead to the most extensive phase separation of carbon and SiOC clusters (along with $\mathrm{SiO}_{2}$ formation) and thus more vulnerability for oxidation. As a result, high pyrolysis temperatures lead to more weight gain before the onset of noticeable weight loss at $>800{ }^{\circ} \mathrm{C}$ for the $60 \mathrm{wt} \%$ and $80 \mathrm{wt} \%$ DVB samples. This result is consistent with the oxidation of other SiOC systems. For example, oxidation resistance of $\mathrm{Si}-\mathrm{O}-\mathrm{C}$ materials derived from co-polymers of 30P, 50P and 70P (P means a phenyl molar content to phenyl + methyl groups in the co-polymer) shows that carbon burning proceeds in the temperature range of $600-1000{ }^{\circ} \mathrm{C} .{ }^{29}$ The samples pyrolyzed at $1000{ }^{\circ} \mathrm{C}$ can resist oxidation at $1000{ }^{\circ} \mathrm{C}$ and $1400{ }^{\circ} \mathrm{C}$ during the initial stage of the oxidation. If the sample is pyrolyzed at $1800{ }^{\circ} \mathrm{C}$, however, the residual network is only left with loosely contacted SiC crystallites by selectively removing carbon. ${ }^{30}$ In addition, the high temperature stability of three SiOCs having different amounts of free carbon (ranging from 0 to $60 \%$ of the total amount of carbon) has been studied. ${ }^{31}$ The sample with a low amount of free carbon shows the lowest value of weight loss $(\approx 3 \%)$ and the highest onset temperature $\left(\approx 1500{ }^{\circ} \mathrm{C}\right)$ for the degradation process. The sample with a higher amount of free carbon shows approximately doubled $(\approx 6 \%)$ weight loss and displays a lower onset temperature $\left(\approx 1450{ }^{\circ} \mathrm{C}\right)$.

In earlier work related to SiOC oxidation, ${ }^{26}$ it is believed that the oxidized $\mathrm{SiO}_{2}$ forms a protective layer and can effectively hinder the diffusion of oxygen. The interior of SiOC remains at a very low effective oxygen pressure and the SiOC network largely remains stable. When a $\mathrm{SiO}_{2}$ layer forms on the surface of the SiOC matrix, further oxidation can be effectively prevented. In Fig. 3, however, at $1400{ }^{\circ} \mathrm{C}$ pyrolysis temperature, for $60 \mathrm{wt} \% \mathrm{DVB}$ and $80 \mathrm{wt} \%$ DVB samples, there is a drastic weight loss. We believe that the high carbon content of our SiOC system has created a more unique system regarding thermal degradation. In the studied temperature range (up to $1000{ }^{\circ} \mathrm{C}$ ), the system is thermally stable due to the mutually restraining effect of the free carbon phase and the SiOC phase. As soon as one of these phases (such as carbon) becomes unstable, it creates a more vulnerable system for thermal degradation due to the simultaneous oxidation of the free carbon and SiOC. The low SiOC content is not effective for the formation of a protective $\mathrm{SiO}_{2}$ layer. With the high carbon content in these systems, the stability decreases more significantly than for the SiOC compositions with lower carbon (0 wt \%, $20 \mathrm{wt} \%$, and $40 \mathrm{wt} \%$ DVB) at high temperatures.

Fig. 5 shows the $40 \mathrm{wt} \%$ and $80 \mathrm{wt} \%$ DVB samples with $1400{ }^{\circ} \mathrm{C}$ pyrolysis temperature after the TGA test up to $1000{ }^{\circ} \mathrm{C}$. As both samples show, the amorphous nature of the SiOC remains unchanged. For the $40 \mathrm{wt} \%$ DVB samples, few defects are observed. For the $80 \mathrm{wt} \%$ DVB samples, some surface defects are observed. This is likely a result of SiOC oxidation and weight loss.

\subsection{Electrical conductivity}

For the SiOC samples with different DVB contents, the electrical conductivity between $50{ }^{\circ} \mathrm{C}$ and $400{ }^{\circ} \mathrm{C}$ is plotted as a function of (reciprocal) temperature on a semilogarithmic scale. The results follow the Arrhenius law and activation energy can be derived from the slopes. As seen, the activation energies are fairly low: $0.012 \mathrm{eV}, 0.0042 \mathrm{eV}, 0.0014 \mathrm{eV}, 0.0023 \mathrm{eV}$, and 0.0023 eV for the $0 \mathrm{wt} \%$ DVB, $20 \mathrm{wt} \%$ DVB, $40 \mathrm{wt} \%$ DVB, $60 \mathrm{wt} \% \mathrm{DVB}$, and $80 \mathrm{wt} \%$ DVB samples, respectively; thus, the excessive carbon is the conductor. Depending on the free carbon content in the SiOC, two approaches have been used to describe the electrical properties: the David-Mott model and the percolation of conductive turbostratic carbon.

The David-Mott model applies to systems with low, nonpercolating free carbon content. The essential features for the 

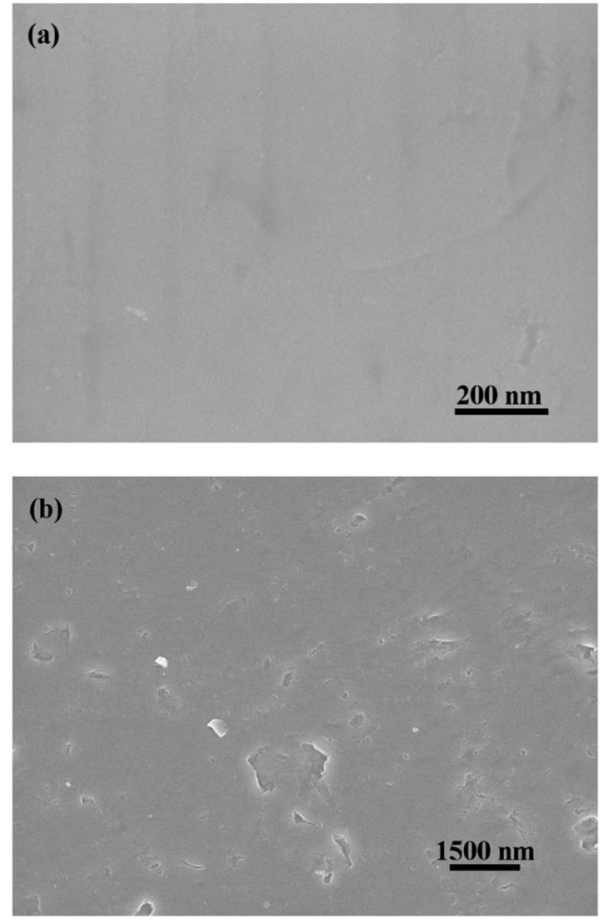

Fig. 5 Microstructures for the (a) $40 \mathrm{wt} \%$ and (b) $80 \mathrm{wt} \%$ DVB samples with $1400{ }^{\circ} \mathrm{C}$ pyrolysis temperature after the TGA test up to $1000{ }^{\circ} \mathrm{C}$.

David-Mott model are the band structure of amorphous semiconductors with narrow tails of localized states at the extremities of the valance and conduction bands as well as a band of localized levels near the middle of the gap. The gaps in the SiOC are due to dangling bonds of $\mathrm{sp}^{2}$ carbon: one on the surface of free carbon and one within the bulk of SiOC. Regular electron band conduction due to the intrinsic conductivity of turbostratic carbon $\left(8 \times 10^{-4} \Omega \mathrm{cm}^{-1}\right)$ predominates the conductivity. ${ }^{24}$ As seen, if the conduction mechanism is based on the bandgap of turbostratic carbon, the conductivity would be very low, on the order of $10^{-11} \mathrm{~S} \mathrm{~cm}^{-1}$ to $10^{-1} \mathrm{~S} \mathrm{~cm}^{-1}$. So far, most of the electrical conductivity studies in this range are for polycarbosilane or polysilazane derived ceramics. ${ }^{32-36}$ For the SiOC systems reported in this study, the carbon content enables the percolation of conductive turbostratic carbon, and the conductivity is orders of magnitude higher.

Fig. 6 shows that at $1400{ }^{\circ} \mathrm{C}$ pyrolysis temperature, $0 \mathrm{wt} \%$ and $20 \mathrm{wt} \%$ DVB samples have much lower electrical conductivity compared to $\geq 40 \mathrm{wt} \%$ DVB compositions. At $0 \mathrm{wt} \% \mathrm{DVB}$, the conductivity changes from $5.08 \times 10^{-7} \mathrm{~S} \mathrm{~cm}^{-1}$ at room temperature to $3.89 \times 10^{-5} \mathrm{~S} \mathrm{~cm}^{-1}$ at $650{ }^{\circ} \mathrm{C}$ before dropping significantly. At $20 \mathrm{wt} \% \mathrm{DVB}$, the conductivity increases by $4-5$ orders of magnitude, from $0.05 \mathrm{~S} \mathrm{~cm}^{-1}$ at room temperature to $0.16 \mathrm{~S} \mathrm{~cm}^{-1}$ at $400{ }^{\circ} \mathrm{C}$ before dropping significantly. The carbon content and interconnectivity of the carbon network are believed to exert a major influence on the electrical conductivity. High fractions of carbon with $\mathrm{sp}^{2}$ hybridization result in high conductivities of the pyrolyzed SiOCs. For the $0 \mathrm{wt} \%$ and $20 \mathrm{wt} \%$ DVB compositions, we believe that the low conductivity is contributed by the band structure of carbon atoms. Above $\geq 40 \mathrm{wt} \% \mathrm{DVB}$, the free carbon content increase due to the carbon-rich nature results in percolating

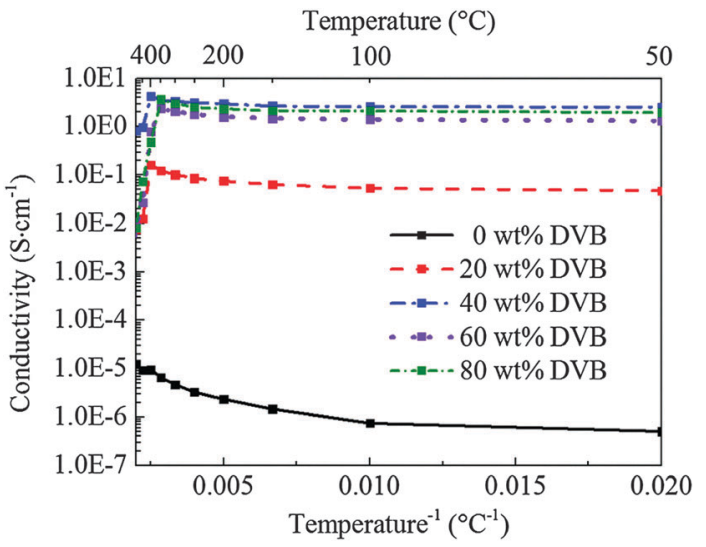

Fig. 6 Electrical conductivity change vs. testing temperature for SiOCs after pyrolysis at $1400{ }^{\circ} \mathrm{C}$ with different DVB contents.

conductive network formation. At $40 \mathrm{wt} \% \mathrm{DVB}$, the conductivity changes from $2.58 \mathrm{~S} \mathrm{~cm}^{-1}$ at room temperature to $4.28 \mathrm{~S} \mathrm{~cm}^{-1}$ at $400{ }^{\circ} \mathrm{C}$ before dropping significantly. At $60 \mathrm{wt} \% \mathrm{DVB}$, the conductivity changes from $1.34 \mathrm{~S} \mathrm{~cm}^{-1}$ at room temperature to $2.38 \mathrm{~S} \mathrm{~cm}^{-1}$ at $350{ }^{\circ} \mathrm{C}$ before dropping significantly. At $80 \mathrm{wt} \%$ $\mathrm{DVB}$, the conductivity changes from $1.97 \mathrm{~S} \mathrm{~cm}^{-1}$ at room temperature to $3.66 \mathrm{~S} \mathrm{~cm}^{-1}$ at $350{ }^{\circ} \mathrm{C}$ before dropping significantly. So far $4.28 \mathrm{~S} \mathrm{~cm}^{-1}$ is the highest electrical conductivity reported for the SiOC pyrolyzed at $\leq 1400{ }^{\circ} \mathrm{C}$.

Fig. 6 also shows that the electrical conductivity initially increases up to $\sim 400{ }^{\circ} \mathrm{C}$ before decreasing drastically. The sudden increase and the sharp drop following that in electrical conductivity observed are related to the further phase separation into free carbon and SiC crystallites (Fig. 7) as well as the surface SiOC oxidation to $\mathrm{SiO}_{2}$ (Fig. 8). With the simultaneous presence of high temperature and electrical field, the SiOC structure is destabilized to a small extent, as shown by the more obvious SiC XRD peaks and the disappearance of the carbon XRD peak after the electrical conductivity measurements (Fig. 7). The Ag XRD peak is from the conducting paste placed on the sample surface during the electrical conductivity measurements and should be ignored. The TEM images in Fig. 7 show the amorphous, pseudohomogeneous microstructure before the electrical conductivity measurement. After the electrical conductivity measurement, however, very large carbon nanotubes (though very few) and SiC crystallites are observed. As a result, the electrical conducting path is compromised.

Fig. 8 shows the conductivity change with the pyrolysis temperatures for the $80 \mathrm{wt} \%$ DVB sample. At $1200{ }^{\circ} \mathrm{C}$, the conductivity increases from $0.14 \mathrm{~S} \mathrm{~cm}^{-1}$ at room temperature to $0.67 \mathrm{~S} \mathrm{~cm}^{-1}$ at $400{ }^{\circ} \mathrm{C}$ before decreasing drastically. At $1300{ }^{\circ} \mathrm{C}$, the conductivity increases from $0.47 \mathrm{~S} \mathrm{~cm}^{-1}$ at room temperature to $1.30 \mathrm{~S} \mathrm{~cm}^{-1}$ at $350{ }^{\circ} \mathrm{C}$ before decreasing drastically. At $1400{ }^{\circ} \mathrm{C}$ pyrolysis temperature, the conductivity ranges from $1.97 \mathrm{~S} \mathrm{~cm}^{-1}$ at room temperature to $3.66 \mathrm{~S} \mathrm{~cm}^{-1}$ at $350{ }^{\circ} \mathrm{C}$. An increase in conductivity with increasing pyrolysis temperature is a result of increasing free carbon content and possibly a structural modification leading to ordering of the graphitic domains (transformation of $\mathrm{sp}^{3}$ into $\mathrm{sp}^{2}$ ). Based on our earlier work and the literature, a 


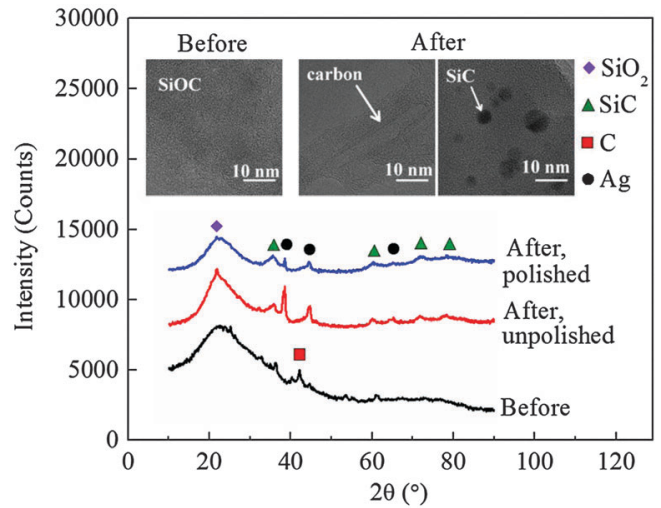

Fig. 7 Phase and microstructural changes for the SiOC system with 80 wt\% DVB before and after the electrical conductivity measurements. Both the polished and unpolished samples are evaluated after the electrical conductivity measurements.

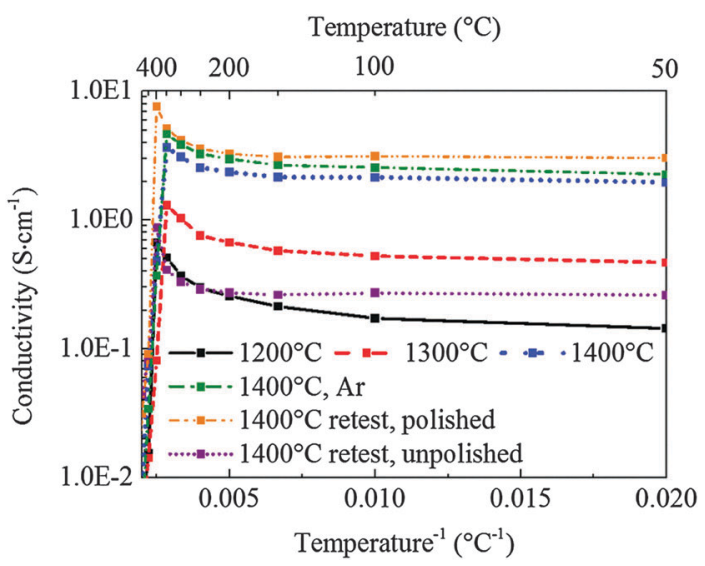

Fig. 8 Conductivity change with the pyrolysis temperatures for the SiOC with $80 w t \%$ DVB in air and high purity Ar atmospheres.

network of graphite-like lamellae of a few atom layers in size can be assumed. ${ }^{37}$ Comparing with Table 2 and Fig. 1, it further demonstrates that while the total free carbon content is critical for electrical conductivity, the phase separation and the conductive path formation cannot be ignored. Higher pyrolysis temperature leads to more organized free carbon and thus higher electrical conductivity, even if the total free carbon content is lower. Fig. 8 further shows that in an Ar inert atmosphere, the electrical conductivity is $4.64 \mathrm{~S} \mathrm{~cm}^{-1}$, much higher than that in air and some of the literature reported values. ${ }^{38}$ SiOC surface oxidation to a thin layer of $\mathrm{SiO}_{2}$ contributes to the decrease of electrical conductivity. With a further increase in temperature after $400{ }^{\circ} \mathrm{C}$, the conductivity also drastically decreases. The drastic decrease in conductivity with the measurement temperature is related to phase separation (Fig. 7) and surface oxidation (Fig. 8), as mentioned earlier. In Fig. 8, we have measured the electrical conductivity the second time for the unpolished and polished samples that have been gone through the electrical conductivity measurement. For the unpolished samples, the electrical conductivity remains low; the values are in-between those of samples pyrolyzed at temperatures $1200{ }^{\circ} \mathrm{C}$ and $1300{ }^{\circ} \mathrm{C}$. For the polished samples, the electrical conductivity is actually higher for the second time electrical conductivity measurement ( 7.63 vs. $\left.3.66 \mathrm{~S} \mathrm{~cm}^{-1}\right)$. This is consistent with the high purity $\mathrm{Ar}$ atmosphere measurement in Fig. 8.

\section{Conclusions}

This paper focuses on the thermophysical characteristics and electrical conductivity of a PHMS and DVB derived SiOC system. These SiOCs are stable up to $1000{ }^{\circ} \mathrm{C}$ in air with $<0.5 \mathrm{wt} \%$ change, contributed largely by the interlocking SiOC and free carbon microstructures. The electrical conductivity increases from room temperature up to $400{ }^{\circ} \mathrm{C}$ and with the DVB content as well as with the pyrolysis temperature. In air, the highest electrical conductivity is $4.28 \mathrm{~S} \mathrm{~cm}^{-1}$ at $400{ }^{\circ} \mathrm{C}$. In Ar, the highest electrical conductivity is $4.64 \mathrm{~S} \mathrm{~cm}^{-1}$ at $350{ }^{\circ} \mathrm{C}$. Such high electrical conductivity is closely related to the percolating free carbon network.

\section{Acknowledgements}

The authors acknowledge the financial support from the US Office of Naval Research under grant number N000141410446.

\section{References}

1 P. Greil, Adv. Eng. Mater., 2000, 2, 339.

2 E. Bernardo, L. Fiocco, G. Parcianello, E. Storti and P. Colombo, Materials, 2014, 7, 1927.

3 P. H. Mutin, J. Sol-Gel Sci. Technol., 1999, 14, 27.

4 J. Li and K. Lu, J. Am. Ceram. Soc., 2015, 98, 2357.

5 P. Dibandjo, S. Dire, F. Babonneau and G. D. Soraru, Glass Technol.: Eur. J. Glass Sci. Technol., Part A, 2008, 49, 175-178.

6 A. Saha and R. Raj, J. Am. Ceram. Soc., 2007, 90, 578.

7 A. Saha, R. Raj and D. L. Williamson, J. Am. Ceram. Soc., 2006, 89, 2188.

8 H. Brequel, J. Parmentier, S. Walter, R. Badheka, G. Trimmel, S. Masse, J. Latournerie, P. Dempsey, C. Turquat, A. DesmartinChomel, L. Le Neindre-Prum, U. A. Jayasooriya, D. Hourlier, H. J. Kleebe, G. D. Soraru, S. Enzo and F. Babonneau, Chem. Mater., 2004, 16, 2585.

9 P. Colombo, G. Mera, R. Riedel and G. D. Sorarù, J. Am. Ceram. Soc., 2010, 93, 1805.

10 F. Ji, Y. L. Li, J. M. Feng, D. Su, Y. Y. Wen, Y. Feng and F. Hou, J. Mater. Chem., 2009, 19, 9063.

11 X. Liu, K. Xie, J. Wang, C. M. Zheng and Y. Pan, J. Mater. Chem., 2012, 22, 19621.

12 M. Graczyk-Zajac, M. Wimmer, C. Neumann and R. Riedel, J. Solid State Electrochem., 2015, 19, 2763.

13 V. S. Pradeep, D. G. Ayana, M. Graczyk-Zajac, G. D. Soraru and R. Riedel, Electrochim. Acta, 2015, 157, 41.

14 Y. D. Blum, D. B. MacQueen and H. J. Kleebe, J. Eur. Ceram. Soc., 2005, 25, 143. 
15 E. Ionescu, H. J. Kleebe and R. Riedel, Chem. Soc. Rev., 2012, 41, 5032.

16 K. W. Wang, B. S. Ma, X. Q. Li, Y. G. Wang and L. N. An, J. Am. Ceram. Soc., 2014, 97, 2135.

17 H. J. Kleebe, G. Gregori, F. Babonneau, Y. D. Blum, D. B. MacQueen and S. Masse, Int. J. Mater. Res., 2006, 97, 699.

18 G. Gregori, H. J. Kleebe, Y. D. Blum and F. Babonneau, Int. J. Mater. Res., 2006, 97, 710.

19 S. Martinez-Crespiera, E. Ionescu, H. J. Kleebe and R. Riedel, J. Eur. Ceram. Soc., 2011, 31, 913.

20 K. J. Kim, J. H. Eom, Y. W. Kim and W. S. Seo, J. Eur. Ceram. Soc., 2015, 35, 1355.

21 F. Kolář, V. Machovič, J. Svítilová and L. Borecká, Mater. Chem. Phys., 2004, 86, 88.

22 H. J. Kleebe and Y. D. Blum, J. Eur. Ceram. Soc., 2008, 28, 1037.

23 Q. S. Ma and Z. H. Chen, Rare Met. Mater. Eng., 2007, 36, 619.

24 J. Cordelair and P. Greil, J. Eur. Ceram. Soc., 2000, 20, 1947.

25 J. K. Li, K. Lu, T. S. Lin and F. Y. Shen, J. Am. Ceram. Soc., 2015, 98, 1753.

26 G. M. Renlund, S. Prochazka and R. H. Doremus, J. Mater. Res., 1991, 6, 2716.

27 C. M. Brewer, D. R. Bujalski, V. E. Parent, K. Su and G. A. Zank, J. Sol-Gel Sci. Technol., 1999, 14, 49.
28 M. A. Mazo, A. Nistal, A. C. Caballero, F. Rubio, J. Rubio and J. L. Oteo, J. Eur. Ceram. Soc., 2013, 33, 1195.

29 M. Narisawa, Materials, 2010, 3, 3518.

30 M. Narisawa, T. Hasegawa, K. Okamura, M. Itoh, T. Apple, K. V. Moraes and L. V. Interrante, J. Mater. Res., 2002, 17, 214. 31 G. D. Soraru and D. Suttor, J. Sol-Gel Sci. Technol., 1999, 14, 69.

32 E. Bouillon, F. Langlais, R. Pailler, R. Naslain, F. Cruege, P. V. Huong, J. C. Sarthou, A. Delpuech, C. Laffon, P. Lagarde, M. Monthioux and A. Oberlin, J. Mater. Sci., 1991, 26, 1333.

33 E. Bouillon, D. Mocaer, J. F. Villeneuve, R. Pailler, R. Naslain, M. Monthioux, A. Oberlin, C. Guimon and G. Pfister, J. Mater. Sci., 1991, 26, 1517.

34 C. Haluschka, C. Engel and R. Riedel, J. Eur. Ceram. Soc., 2000, 20, 1365.

35 A. M. Hermann, Y. T. Wang, P. A. Ramakrishnan, D. Balzar, L. N. An, C. Haluschka and R. Riedel, J. Am. Ceram. Soc., 2001, 84, 2260.

36 S. Trassl, M. Puchinger, E. Rossler and G. Ziegler, J. Eur. Ceram. Soc., 2003, 23, 781.

37 J. Robertson, Adv. Phys., 1986, 35, 317.

38 D. S. Ruan, Y. L. Li, L. Wang, D. Su and F. Hou, J. Sol-Gel Sci. Technol., 2010, 56, 184. 